\title{
(1) astum \\ Groin complications in endovascular mechanical thrombectomy for acute ischemic stroke: a 10-year single center experience
}

\author{
Veer A Shah, ${ }^{1}$ Coleman 0 Martin, ${ }^{1}$ Angela M Hawkins, ${ }^{1}$ William E Holloway, ${ }^{1}$ \\ Shilpa Junna, ${ }^{2}$ Naveed Akhtar ${ }^{1}$
}

${ }^{1}$ Marion Bloch Neuroscience Institute, St. Luke's Plaza, Kansas City, Missouri, USA ${ }^{2}$ University of Missouri-Kansas City School of Medicine, Kansas City, Missouri, USA

\section{Correspondence to} Dr Coleman 0 Martin, Marion Bloch Neuroscience Institute, St. Luke's Plaza, 4401 Wornall Road, Kansas City, MO 64111, USA; comartin@saint-lukes.org

Received 24 March 2015 Revised 1 May 2015 Accepted 5 May 2015 Published Online First 22 May 2015

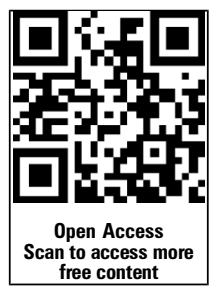

CrossMark

To cite: Shah VA Martin CO, Hawkins AM et al. J Neurolntervent Surg 2016:8:568-570.

\section{ABSTRACT}

Background The increasing utilization of balloon guide catheters (BGCs) in thrombectomy therapy for ischemic stroke has led to concerns about large-bore sheaths causing vascular groin complications.

Objective To retrospectively assess the impact of large large-bore sheaths and vascular closure devices on groin complication rates at a comprehensive stroke center over a 10 -year period.

Methods Radiological and clinical records of patients with acute ischemic stroke who underwent mechanical endovascular therapy with an $8 \mathrm{Fr}$ or larger sheaths were reviewed. A groin complication was defined as the formation of a groin hematoma, retroperitoneal hematoma, femoral artery pseudoaneurysm, or the need for surgical repair. Information collected included size of sheath, type of hemostatic device, and anticoagulation status of the patient. Blood bank records were also analyzed to identify patients who may have had an undocumented blood transfusion for a groin hematoma. Results A total of 472 patients with acute ischemic stroke who underwent mechanical thrombectomy with a sheath and BGC sized 8Fr or larger were identified. 260 patients (55.1\%) had tissue Plasminogen Activator (tPA) administered as part of stroke treatment. Vascular closure devices were used in $97.9 \%$ of cases $(n=462)$. Two patients were identified who had definite groin complications and a further two were included as having possible complications. There was a very low rate of clinically significant groin complications $(0.4-0.8 \%)$ associated with the use of large-bore sheaths.

Conclusions These findings suggest that concerns for groin complications should not preclude the use of BGCs and large-bore sheaths in mechanical thrombectomy for acute ischemic stroke.

\section{INTRODUCTION}

Cerebral arterial thrombectomy for the treatment of acute ischemic stroke has been available in the USA outside clinical trials for the past decade. There has been considerable evolution in thrombus retrieval technology resulting in rates of good recanalization climbing from $48 \%$ (TIMI grade 2 or 3 ) in the MERCI trial in $2004,{ }^{1}$ to greater than $86 \%$ (modified TICI grade $2 \mathrm{~b}$ or 3 ) reported in the EXTEND-IA trial in $2015 .^{2}$ One component that has evolved only modestly over this period is the reliance upon the balloon guide catheter (BGC), available since 2001. This type of catheter allows temporary proximal arterial occlusion during removal of the thrombus. Because BGCs are relatively large $(7 \mathrm{Fr}-9 \mathrm{Fr})$, some neurointerventionalists have been reluctant to use them because of concerns relating to groin complications in a population of patients who are frequently anticoagulated or who have received tissue Plasminogen Activator (tPA).

To circumvent these concerns, many neurointerventionalists instead rely on thrombectomy devices through standard guide catheters, distal access catheters and via $6 \mathrm{Fr}$ long sheaths. However, Nguyen and colleagues ${ }^{3}$ reported inferior recanalization rates and poorer clinical outcomes without the use of a BGC as the delivery platform for stent retriever devices. As such, use of a BGC and the requisite larger sheath appears to be of benefit provided groin complications do not negate good clinical outcomes.

Femoral artery complications have been described by several authors in the setting of acute stroke $^{4}$ and other interventions, ${ }^{5}{ }^{6}$ however, few have correlated the size of the sheath and type of vascular closure device used with the incidence of such complications. We aimed to retrospectively evaluate the impact of large sheath sizes and vascular closure devices on groin complications, in a high-volume neurointerventional center.

\section{METHODS}

The study institution is a Comprehensive Stroke Center certified by The Joint Commission, averaging 682 annual ischemic stroke admissions over a period spanning 2005-2014. Neurointervention rates over this period have ranged between $8.3 \%$ and $21 \%$ of patients presenting with acute stroke. All aspects of the thrombectomy procedure (including groin puncture and vascular closure device deployment, if used) were performed by fellowship trained neurointerventional specialists. Our neurointerventional patient database was reviewed for all patients who underwent endovascular mechanical thrombectomy for acute ischemic stroke between 1 January 2005 and 31 December 2014. Inclusion criteria included all patients who had a sheath and BGC sized $8 \mathrm{Fr}$ or $9 \mathrm{Fr}$ used during their procedure. Only $8 \mathrm{Fr}$ and $9 \mathrm{Fr}$ sheath sizes were used for BGCs at our study institution. Any patients who had a smaller sized sheath used were excluded. Arteriotomy access in all cases was performed without ultrasound guidance. Procedure reports were used to obtain information on: (1) the use of a micro-puncture kit for femoral artery 
access, (2) the size of the sheath, (3) the type of vascular closure device used (if any), (4) whether the patient received preprocedure intravenous (IV) tPA and/or intra-procedural intra-arterial (IA) tPA, and (5) whether a pelvic angiogram was performed prior to hemostasis. Electronic Medical Records (EMR) were reviewed for each patient to determine preprocedure anticoagulant use and demographic information including age and gender. Patients on antiplatelet agents were not considered to be anticoagulated. Patients were kept on bed-rest for a minimum of $6 \mathrm{~h}$ post-procedure.

Patient radiological reports were reviewed for evidence of ultrasound imaging of the groin or CT of the abdomen and/or pelvis, up to 30 days post-procedure. EMR were also examined for descriptions of complications at the groin site. Groin complications were sub-classified into 'definite' or 'possible'. A definite groin complication was defined as groin hematoma, retroperitoneal hematoma or femoral artery pseudoaneurysm meeting any of the following criteria: (a) requiring surgical or radiological intervention to treat, (b) requiring at least 1 unit of blood transfusion, (c) causing $>3 \mathrm{~g}$ drop in hemoglobin, (d) causing a $10 \%$ drop in hematocrit, (e) requiring surgical intervention to correct vessel injury due to vascular closure device deployment, or (f) contributing to or resulting in the death of the patient. A possible groin complication was defined as blood transfusion within $72 \mathrm{~h}$ of the thrombectomy procedure without a clear documented explanation as to the reason for the transfusion. Other hematomas not meeting the above criteria were not included the analysis.

Finally, patients in our neurointerventional database were cross-checked with the hospital blood-bank records for a specified time period (2005-2014) to identify any patient who may have had a blood transfusion during their admission for stroke treatment. This was carried out to minimize the possibility of the EMR failing to document a significant groin hematoma. This study was approved by the local institutional review board.

\section{RESULTS}

A total of 472 patients with acute ischemic stroke who underwent mechanical thrombectomy with a $8 \mathrm{Fr}$ or larger sheath and BGC were identified. The mean age $\pm S D$ was $70 \pm 16$ years, and

Table 1 Demographic and pre-procedural information

\begin{tabular}{lll}
\hline Characteristic & N & Percent \\
\hline Total cases & 472 & \\
Gender & & \\
$\quad$ Male & 236 & 50 \\
$\quad$ Female & 236 & 50 \\
Age & & \\
$\quad$ Mean $\pm S D$ & $70 \pm 16$ & \\
Anticoagulation status & & 12.5 \\
$\quad$ Warfarin & 59 & \\
$\quad$ Mean INR \pm SD (n=55) & $1.6 \pm 0.5$ & 0.2 \\
Rivaroxaban & 1 & 87.3 \\
$\quad$ No prior anticoagulation & 412 & 5.9 \\
$\quad$ Patients with INR $>1.7$ & 28 & 2.1 \\
Dual Antiplatelet therapy & 10 & \\
Thrombolytic therapy & & 21.8 \\
IA tPA & 103 & 26.1 \\
IV tPA & 123 & 7.2 \\
IV and IA tPA & 34 & 44.9 \\
$\quad$ No tPA & 212 & \\
\hline IA, intra-arterial; tPA, tissue Plasminogen Activator. &
\end{tabular}

$50 \%$ were female. Full demographic information is noted in table 1.

Two hundred and sixty patients $(55.1 \%)$ had tPA administered as part of stroke treatment. Out of these, 103 patients $(21.8 \%)$ had intra-arterial tPA administered while 123 patients (26.1\%) had intravenous tPA administered. 34 patients $(7.2 \%)$ had both intra-arterial and intravenous tPA, while 212 patients (44.9\%) had no tPA given. 59 patients $(12.5 \%)$ were noted to be on warfarin, with a mean INR of 1.6 (range 0.9-2.9). Only 28 patients $(5.9 \%)$ had an INR $>1.7$. A single patient was taking an oral Xa-inhibitor and no patients were taking a direct thrombin inhibitor during the time of review.

Four hundred and forty-eight patients (95\%) were treated using an $8 \mathrm{Fr}$ sheath and BGC and 24 patients (5\%) had a $9 \mathrm{Fr}$ sheath and BGC used. The use of a micro-puncture kit for arterial access was documented in 185 cases (39.2\%). Vascular closure devices were used in $97.9 \%$ of cases $(n=462)$. The $8 \mathrm{Fr}$ Angioseal VIP (St. Jude Medical, St Paul, Minnesota, USA) was the most common vascular closure device, used in 443 patients (93.9\%) (table 2). A variety of other devices, which are labeled for use in $6 \mathrm{Fr}$ sheaths, were also used in a small minority of cases. A pelvic angiogram was documented in 199 cases (42.2\%).

Only two patients were identified whom had definite groin complications that met the criteria listed above. The first patient, who was on Warfarin and admitted with an INR of 1.5, had a groin hematoma and pseudoaneurysm post-procedure that was treated by the interventional radiology service with thrombin injection. Although there was a drop in hemoglobin from $13 \mathrm{~g}$ to $10.7 \mathrm{~g}$, the patient did not undergo blood transfusion and the hematoma was otherwise allowed to resolve without intervention.

The second patient, who was also on Warfarin and admitted with an INR of 1.2, had a groin hematoma post procedure. She was also noted to have a decrease in hemoglobin from $12.6 \mathrm{~g}$ to $6.5 \mathrm{~g}$ attributed to the hematoma and was transfused 2 units of blood. For both patients an 8Fr sheath and BGC were used, with the Angioseal as the closure device. Both patients had a pelvic angiogram performed post-procedure that was normal.

A search of blood bank records revealed two additional stroke patients who had blood transfusions within $48 \mathrm{~h}$ of groin puncture. One patient had a history or thalassemia minor and iron deficiency anemia. He demonstrated a drop from his baseline hemoglobin of 11.0-8.6 g post-procedure. Five passes were made with the retrieval device and the estimated blood loss was $250 \mathrm{~mL}$. The other patient had no listed confounding hematologic diagnoses and demonstrated a hemoglobin drop from 10.3

Table 2 Sheath size and method of hemostasis

\begin{tabular}{lrr}
\hline Characteristic & N & Percent \\
\hline Size of sheath & & \\
8 Fr sheath and guide catheter & 448 & 94.9 \\
9 Fr sheath and guide catheter & 24 & 5.1 \\
Method of hemostasis & & \\
Angioseal VIP (St. Jude Medical, St Paul, Minnesota, USA) & 443 & 93.9 \\
Mynx (AccessClosure, Mountain View, California, USA) & 1 & 0.2 \\
Vasoseal (Datascope, Montvale, New Jersey, USA) & 3 & 0.6 \\
Starclose (Abbott Vascular, Abbott Park, Illinois, USA) & 1 & 0.2 \\
Perclose (Abbott Vascular, Abbott Park, Illinois, USA) & 14 & 3.0 \\
Manual compression & 10 & 2.1 \\
\hline
\end{tabular}


to $7.0 \mathrm{~g}$. Two passes were made with the retrieval device with an estimated blood loss of $100 \mathrm{~mL}$. In neither patient's clinical notes was a groin hematoma nor bleeding described. Neither patient had groin ultrasound imaging nor CT of the abdomen or pelvis to lend support to a groin complication as the source of the anemia. As such, both of these patients have been classified as possible groin complications.

There were no retroperitoneal hematomas requiring transfusion nor intervention. There were no deaths attributed to groin complications. The overall definite groin complication rate was therefore $0.4 \%(n=2)$, with a definite and possible groin complication rate of $0.8 \%(n=4)$.

\section{DISCUSSION}

The main finding in this study was the low rate of groin complication associated with large bore sheaths in thrombectomy therapy. This reflects favorably on one aspect of using BGC during the thrombectomy procedure. BGCs have been associated with superior outcomes for patients receiving thrombectomy therapy. An analysis from the North American Solitaire Stent-Retriever Acute Stroke registry showed that the use of a BGC (versus no BGC) was associated with a shorter procedure time ( 120 vs $161 \mathrm{~min} ; \mathrm{p}=0.02)$, a higher rate of TICI 3 recanalization $(53.0 \%$ vs $32.5 \% ; \mathrm{p}<0.001)$, and a higher rate of good clinical outcome $(51.6 \%$ vs $35.8 \% ; \mathrm{p}=0.02) .{ }^{3}$ Recent randomized clinical trials using stent retriever technology have shown efficacy for the use of endovascular intervention in stroke treatment. $^{2} 78$ It appears likely that these studies will result in an increase in procedure rates for acute ischemic stroke. This points to the importance of continued study of procedure complication rates including complications of arterial access.

Arterial puncture site complications during endovascular procedures infrequently cause significant morbidity to the patient, ranging from retroperitoneal hemorrhage and pseudoaneurysm formation to overt arterial bleeding. This in turn can lead to increased hospital time and a need for transfusion or intervention. In addition, achieving hemostasis can be a challenge in patients on anticoagulation, uncooperative patients and those with morbid obesity.

In our study, almost all patients (97.9\%) had a vascular closure device used. Larger systematic reviews and meta-analyses reviewing groin complications, usually in the setting of comparing various vascular closure devices and manual compression, have tended to underrepresent sheath sizes greater than 7Fr. The ISAR-CLOSURE study was a randomized clinical trial that showed non-inferiority of vascular closure devices to manual compression in terms of vascular access-site complications and reduced time to hemostasis, in patients undergoing transfemoral coronary angiography. ${ }^{9}$ However, only 6-Fr sized sheaths were used. A meta-analysis by Das and colleagues comparing vascular closure devices and manual compression in interventional radiologic procedures showed no statistically significant difference between the two, although marginally fewer femoral complications with closure devices were noted. Sheaths $>8$ Fr were excluded. ${ }^{6}$

It has been suggested that increasing sheath size leads to a sheath-artery size mismatch and a larger entry site in the artery, requiring longer periods of manual pressure and possibly longer period of bed rest after sheath removal. ${ }^{10}$ Most studies evaluating groin complications do so in the context of femoral arterial catheterization during percutaneous coronary interventions (PCIs). The use of arterial sheaths with diameter $>6 \mathrm{Fr}$ have been identified as an independent predictor of vascular complications and major femoral artery bleeding, with incidences ranging from $1 \%$ to $9 \% .{ }^{11-15}$ Use of arterial sheaths $>8$ Fr has also been reported to be an independent predictor of retroperitoneal hematoma after PCI. ${ }^{10} 16$

Other authors have evaluated groin complications in patients who underwent peripheral vascular interventions (PVI). In a retrospective study of the Vascular Study Group of New England (VSGNE) database, Kalish et $a l^{17}$ noted an overall postprocedural groin hematoma rate after PVI of $4.5 \%$ and a rate of combined moderate and major hematoma of $0.8 \%$. A sheath size $>6 \mathrm{Fr}$ was found to be a risk factor of groin hematoma. In addition, interventional procedures usually require some type of antithrombotic medication, and intra-procedural (antiplatelet or anticoagulant) or post-procedural medications (intravenous heparin) have been shown to increase the risks for groin hematoma in some studies ${ }^{18}$ but not in others. ${ }^{17}$

Our cohort of patients is similar to those described in other international stroke trials, with $12.7 \%$ on anticoagulation on admission and 5.9\% of total patients having an INR $>1.7 .{ }^{19}$ Our puncture site complication rate was slightly less than that reported by Applegate and colleagues ${ }^{20}$ who summarized complications of Angioseal deployment in 3898 patients. This retrospective study demonstrated a minor complication (hematoma, arteriovenous fistula, or pseudo-aneurysm) rate of $0.8 \%$ and major complication (vascular death, vascular repair, vessel occlusion, or bleeding with $>3 \mathrm{~g}$ hemoglobin drop) rate in $0.6 \%$ of patients.

In our study, the number of groin complications was too low to meaningfully infer possible relationships between groin complications and anticoagulation, thrombolysis, antiplatelet therapy and type of closure device use. Being that all groin punctures and closure device deployments were performed by neurointerventional attending physicians, it is conceivable that practitioner experience may have played a role. Weaknesses of the study include a single-center retrospective design and its reliance on accurate medical record keeping and coding that could have resulted in a reduced retrospective detection rate. This was in part mitigated this by carefully reviewing all clinical, radiological and blood bank records associated with the patients' admission for stroke treatment. Lastly, this analysis excluded non-clinically significant hematomas and does not represent the rate of minor groin hematoma complications.

\section{CONCLUSION}

In our series, there is a very low rate $(0.4-0.8 \%)$ of clinically significant groin complications associated with the use of $8 \mathrm{Fr}$ and 9Fr sheaths. Concerns for vascular groin complications should not preclude the use of large-bore sheaths and BGCs in the endovascular treatment of stroke.

Correction notice This article has been corrected since it published Online First. The OA licence has now been added.

Contributors All authors participated in drafting the article and revising it critically for important intellectual content. All authors made substantial contributions to conception and design, acquisition of the data, and analysis and interpretation of the data. All authors provided final approval of the version to be published.

Competing interests None declared.

Ethics approval Instiutional Review Board of St. Luke's Plaza, Kansas city.

Provenance and peer review Not commissioned; externally peer reviewed.

Data sharing statement The authors are willing to share spreadsheets from their data extraction on request.

Open Access This is an Open Access article distributed in accordance with the Creative Commons Attribution Non Commercial (CC BY-NC 4.0) license, which permits others to distribute, remix, adapt, build upon this work non-commercially, and license their derivative works on different terms, provided the original work is properly cited and the use is non-commercial. See: http://creativecommons.org/ licenses/by-nc/4.0/ 


\section{REFERENCES}

1 Smith WS, Sung G, Starkman S, et al. Safety and efficacy of mechanical embolectomy in acute ischemic stroke: results of the MERCI trial. Stroke 2005;36:1432-8.

2 Campbell BC, Mitchell PJ, Kleinig TJ, et al. Endovascular therapy for ischemic stroke with perfusion-imaging selection. N Engl J Med 2015;372:1009-18.

3 Nguyen TN, Malisch T, Castonguay AC, et al. Balloon guide catheter improves revascularization and clinical outcomes with the Solitaire device: analysis of the North American Solitaire Acute Stroke Registry. Stroke 2014;45:141-5.

4 Akins PT, Amar AP, Pakbaz RS, et al. Complications of endovascular treatment for acute stroke in the SWIFT trial with solitaire and Merci devices. AJNR Am J Neuroradiol 2014:35:524-8.

5 Fargen KM, Velat GJ, Lawson MF, et al. Occurrence of angiographic femoral artery complications after vascular closure with Mynx and AngioSeal. J Neurointerv Surg 2013;5:161-4.

6 Das R, Ahmed K, Athanasiou T, et al. Arterial closure devices versus manual compression for femoral haemostasis in interventional radiological procedures: a systematic review and meta-analysis. Cardiovasc Intervent Radiol 2011;34:723-38.

7 Goyal M, Demchuk AM, Menon BK, et al. Randomized assessment of rapid endovascular treatment of ischemic stroke. N Engl J Med 2015;372:1019-30.

8 Berkhemer OA, Fransen PS, Beumer D, et al. A randomized trial of intraarteria treatment for acute ischemic stroke. N Engl J Med 2015;372:11-20.

9 Schulz-Schupke S, Helde S, Gewalt S, et al. Comparison of vascular closure devices vs manual compression after femoral artery puncture: the ISAR-CLOSURE randomized clinical trial. JAMA 2014;312:1981-7.

10 Frank JJ, Kamalakannan D, Kodenchery M, et al. Retroperitoneal hematoma in patients undergoing cardiac catheterization. J Interv Cardiol 2010;23:569-74.

11 Smilowitz NR, Kirtane AJ, Guiry M, et al. Practices and complications of vascular closure devices and manual compression in patients undergoing elective transfemoral coronary procedures. Am J Cardiol 2012;110:177-82.
12 Ahmed B, Piper WD, Malenka $D$, et al. significantly improved vascular complications among women undergoing percutaneous coronary intervention: a report from the Northern New England Percutaneous Coronary Intervention Registry. Circ CardiovasC Interv 2009;2:423-9.

13 Doyle BJ, Ting HH, Bell MR, et al. Major femoral bleeding complications after percutaneous coronary intervention: incidence, predictors, and impact on long-term survival among 17,901 patients treated at the mayo clinic from 1994 to 2005. JACC Cardiovasc Interv 2008;1:202-9.

14 Applegate RJ, Sacrinty MT, Kutcher MA, et al. Trends in vascular complications after diagnostic cardiac catheterization and percutaneous coronary intervention via the femoral artery, 1998 to 2007. JACC Cardiovasc Interv 2008;1:317-26.

15 Arora N, Matheny ME, Sepke C, et al. A propensity analysis of the risk of vascular complications after cardiac catheterization procedures with the use of vascular closure devices. Am Heart J 2007;153:606-11.

16 Trimarchi S, Smith DE, Share D, et al. Retroperitoneal hematoma after percutaneous coronary intervention: prevalence, risk factors, management, outcomes, and predictors of mortality: a report from the BMC2 (Blue Cross Blue Shield of Michigan Cardiovascular Consortium) registry. JACC Cardiovasc Interv 2010;3:845-50.

17 Kalish J, Eslami M, Gillespie D, et al. Routine use of ultrasound guidance in femoral arterial access for peripheral vascular intervention decreases groin hematoma rates. J Vasc Surg 2015;61:1231-8.

18 Castillo-Sang M, Tsang AW, Almaroof $B$, et al. Femoral artery complications after cardiac catheterization: a study of patient profile. Ann Vasc Surg 2010;24:328-35.

19 Nogueira RG, Smith WS, MERCI and Multi MERCI Writing Committee. Safety and efficacy of endovascular thrombectomy in patients with abnormal hemostasis: pooled analysis of the MERCI and multi MERCI trials. Stroke 2009;40:516-22

20 Applegate RJ, Sacrinty M, Kutcher MA, et al. Vascular complications with newer generations of angioseal vascular closure devices. J Interv Cardiol 2006;19:67-74. 